Revue d'histoire de l'Amérique française

REVUE D.HISTOIRE DE L'AMÉRIQUE FRANÇAISE

\title{
Certificats de la mort de Mr Desligneris, 14 mars 1760
}

\section{Jean-Jacques Lefebvre}

Volume 18, numéro 2, septembre 1964

URI : https://id.erudit.org/iderudit/302366ar

DOI : https://doi.org/10.7202/302366ar

Aller au sommaire du numéro

Éditeur(s)

Institut d'histoire de l'Amérique française

ISSN

0035-2357 (imprimé)

1492-1383 (numérique)

Découvrir la revue

Citer ce document

Lefebvre, J.-J. (1964). Certificats de la mort de Mr Desligneris, 14 mars 1760.

Revue d'histoire de l'Amérique française, 18(2), 272-273.

https://doi.org/10.7202/302366ar d'utilisation que vous pouvez consulter en ligne.

https://apropos.erudit.org/fr/usagers/politique-dutilisation/ 
No. 8211

\section{CERTIFFICATS DE LA MORT DE MR DESLIGNERIS 14 mars 1760}

Aujourd'huy Pardevant Les notaires Royaux De la ville et jurisdiction Royale de Montreal y residents Soussignes Sont Comparus Sieurs laurent Domer chirurgien demeurant a Montreal rue Saint françois quartier Bonsecours paroisse Notre Dame Et Michel Roussel dit l'Eveillé Caporal de la Compagnie de desligneris demeurant En garnison a Montreal loge par Billet chez la veuve parmier dit Beaulieu Rue Saint Eloy Sous dite 
paroisse Notre Dame les quels vus La Requete Et Sommation verbale que leur a Eté presentement faite par Dame Marie therese Migeon de la Gauchetierre veuve de francois Marie Marchant Ecuyer sieur Desligneris capitaine dinfanterie chevalier de lordre royal Et Militaire de saint Louis demeurante a Montreal rue Et paroisse Notre Dame ont attesté Et certiffié a tous qu'il appartiendera que le dit Sieur francois Marie Marchant Desligneries est décédé Dans le fort de Niagara Le vingt huit aoust dernier des Blessures qu'il avoit recus En allant au secours dudit fort dans le Combat que les anglois Qui S'en Etoient rendus les maitres dont acte Requis Et octroyé qui fut fait Et passé a Montreal En l'Etude Lan Mil Sep Cent Soixante Le quatorze Mars avant midy Et a led Sr donner signe ledit Roussel declare ne Scavoir Ecrire ni signer de ce Enquis Lecture faite.

domer

Bouron DANRE DE BLANZL

Pour copie. Archives Judiciaires de Montréal.

(Communication de M. Jean-Jacques Lefebvre) 